Mobile tech: Superfood or super fad of Creative Business?

Elvira Bolat ${ }^{1}$

${ }^{1} \mathrm{PhD}, \mathrm{MIDM}$, Senior lecturer in marketing, Bournemouth University

Address: Department of Marketing, Business School, Bournemouth University, Fern Barrow, Poole, BH12 5BB

Email: ebolat@bournemouth.ac.uk

ORCiD: https://orcid.org/0000-0003-0910-0860

Twitter: @Elvira MLady 


\title{
Mobile tech: Superfood or super fad of Creative Business?
}

\begin{abstract}
Purpose - Creative agencies are well-known for pioneering technological transformation due its reliance on information and communication technology. Not surprisingly creative businesses are experimenting with mobile technology, but the extent and the scope of mobile technology deployment, and its impact on innovation practices are under explored. Therefore, the purpose of the paper is to explore the role of mobile technology deployment in innovation practices by, firstly, identifying how mobile technology is deployed in creative businesses and, secondly, discovering the behavioral differences in ways creative agencies deploy mobile technology to facilitate or stimulate innovation practices.
\end{abstract}

Methodology - Innovation practices and mobile technology deployment are studied by interviewing creative business decision-makers from the $31 \mathrm{UK}$ creative agencies. The evolved grounded theory approach is used to analyze the interviews data as well as complimentary documents shared by interviewees. Data was arranged, scanned, coded and categorized using NVivo 10 qualitative data analysis software.

Findings - Applying a capability approach and service innovation practice theoretical perspectives, this grounded theory research discovered three clusters of creative agencies (Clusters A, B and C), which reflect on diverse practices of mobile technology deployment and its impact of innovation practices. Mobile technology is in fact a superfood that with the right combination of resources and capabilities delivers strategic benefits for creative business. We conclude that creative agencies deploy mobile technology extensively, and it is the interaction between mobile technology resources and mobile technology capabilities stimulate and facilitate process and product service innovation practices. A critical reflection on existing research findings against empirical results explaining mobile technology 
deployment in creative agencies has demonstrated overlaps and differences in the results. Results on mobile technology deployment overlap with research on fixed networks and stationary IT. However, no previous studies have explored how mechanisms of combining resources with capabilities affect service innovation practices. This study provides such insights, by specifically investigating the interaction between mobile technology resources and mobile technology capabilities and by reflection on practises across creative agencies. In particular distinct clusters have been identified which demonstrate that depending on organizational commitment of creative businesses to mobile technology deployment, interaction between mobile technology resources and mobile technology capabilities can lead to both service innovation practices, in particular process service innovation practices only (Cluster A) and both process service innovation practices and products service innovation practices (Clusters B and C).

Practical Implications - The understanding of mobile technology deployment process that derives from this paper is particularly significant in showing creative businesses' managers the real value in embracing mobile technology. Considering the clustering of creative agencies based on organisational commitment they have towards mobile technology deployment, this study signals that creative business decision-makers can deploy mobile technology to effectively manage operations or/and produce new solutions.

Originality/Value/Contribution - This paper's main theoretical contribution is in researching mobile technology deployment process using the capability approach. This study defines 'mobile technology capabilities' as a firm's unique practices employed in orchestrating mobile technology resources to create a competitive advantage. Mobile technology capabilities consist of five distinct practices that firms perform to combine and integrate mobile technology resources into organisational processes, namely learning, leading, transforming, leveraging mobile technology resources and solving problems. Moreover, this 
study is first to integrate conceptually service innovation and mobile technology deployment by grounding this conceptualisation in empirical setting, which is creative agencies delivering advertising, marketing, digital design and digital architecture services.

Keywords: mobile technology deployment; mobile technology resources; mobile technology capabilities; service innovation practices; creative business; grounded theory

\section{Introduction}

The strong adoption of mobile technology by consumers and their personal use have encouraged organizations to deploy mobile technology for business purposes (European Commission 2017). Although usually being categorized as one of digital technologies, in the business context mobile technology is touted as innovative and disruptive as true ubiquity and mobility - meaning the use of any personal and/or business mobile devices anytime and anywhere regardless the availability of a connection to the Internet (Bolat 2016) - imply new business approaches. Hence, in this paper mobile technology is regarded as a distinctive digital technology category. Existing studies (i.e. Hameed 2003; Jayaram, Manrai, and Manrai 2015) have found that mobile technology provides a quick response to market needs and opportunities to continuously excite, engage with and benefit customers. These studies, however, mostly address the business-to-consumer (B-to-C) consumer perspective.

We should remember, however, that majority of mobile apps are innovative products created by creative and digital agencies for their business customers. In addition, business-tobusiness (B-to-B) firms are widely using mobile technology to improve their processes. One of many illustrative examples from the B-to-B context is SwiftCloud app that enables 24/7 transactions and procurement, developing personalized relationships with business customers and much more efficient communication - altogether transforming processes of B-to-B organizations and experiences of B-to-B customers. Román, Rodríguez, and Jaramillo (2018) and earlier studies (i.e. Chung, Young, and Choi 2015; Yueh, Lu and Lin 2016) demonstrate 
that, when used during working hours, mobile technology allows B-to-B workforce to be much more productive and satisfied with work. This in turn could stimulate creativity amongst mobile technology business users (Bolat 2016). The above provided Illustrative example and academic claims suggest that mobile technology, just like other digital technologies, stimulate both product and process innovation practices in the B-to-B context. This in turn should enable business growth (Foroudi et al. 2017) and increase the likelihood of business survival (Ortiz-Villajos and Sotoca 2018). However, there is a lack of scholarly evidence about whether and how exactly mobile technology use facilitates or stimulates innovation practices in B-to-B firms.

Despite some previous research conducted by a number of scholars, such as Jayaram, Manrai, and Manrai (2015) and Bolat (2016), on understanding the business perspective on mobile technology adoption, there is a lack of empirical studies to determine whether, similar to stationary desktop IT, mobile technology is a driver of process innovation and a tool that can be used to introduce new products and solutions to the market (product innovation). Another concern in the extant study on mobile technology and its corresponding innovation is the narrow focus on technicality. The majority of studies (i.e. Hameed 2003; Jayaram, Manrai, and Manrai 2015) on the use of mobile technology focus on the technical nature of mobile devices despite the fact that the dynamic nature of the mobile business environment requires a focus on usability that goes beyond the device itself (Bolat 2016).

International Data Corporation (IDC, 2016) predicts that organizations will invest over $\$ 1.1$ trillion by 2020 in mobile technologies, including hardware, software and services. Are these financial efforts substantiated by the role mobile technology plays in transforming business practices, when many businesses use mobile apps as the hottest digital technology (Ehrenhard et al. 2017)? Is mobile technology a superfood or super fad? Addressing the above identified theoretical gaps and practical concerns, this paper aims at meeting two research objectives 
(ROs), to identify how mobile technology is deployed by B-to-B businesses (RO1); to explore whether and how mobile technology deployment facilitates or stimulates B-to-B innovation practices $(\mathrm{RO} 2)$.

When dealing with opportunities relating to mobile technology, creative businesses are first to identify and react to such opportunities (Bolat 2016; Oliver 2017). Creative businesses are driving economic growth across the world with their flexible business models, collaborative approaches to production and innovative uses of digital technologies (Fleischmann, Daniel, and Welters 2017). Moreover, creative businesses occupy a top position in the expansion of mobile technology's benefits, particularly through the emergence of new players, including creative agencies specializing in mobile advertising (Bolat, Kooli and Wright 2016). For these reasons, contextually this study focuses on creative agencies.

Mobile technology deployment and corresponding innovation practices are studied by interviewing creative business decision-makers from the UK creative agencies. The evolved grounded theory approach (Corbin and Strauss 1990) assists in the analysis of interview data. A capability approach, which discerns a firm as a bundle of assets and competences, wherein capabilities imply the use-in-practice analysis of assets and competence deployment, assists in conceptualizing the process of mobile technology deployment and understanding qualitative results. Therefore, the theoretical review of existing research includes a critical review of the capability approach.

What distinguishes this paper is greater insights to the practices of mobile technology deployment amongst creative agencies. Applying a capability approach and service innovation practice theoretical perspectives, this grounded theory research informs B-to-B practitioners that mobile technology is in fact a superfood that with the right combination of mobile technology resources and mobile technology capabilities delivers strategic benefits for creative business. In particular in this study three distinct clusters - three behavioural 
ways - in deploying mobile technology have been identified (Clusters A, B and C). From these behavioural differences, further analysis suggested that depending on organizational commitment of creative businesses to mobile technology deployment, interaction between mobile technology resources and mobile technology capabilities can lead to either process innovation practices only (Cluster A) and/or both process and products innovation practices (Clusters B and C). Hence, depending on amount and combination of elements within the mobile technology superfood bowl, B-to-B organisations can gain different benefits, in this study's case - different innovation practices. However, a set of findings derived from the empirical data requires further confirmation by a larger scale study that examines relationships between mobile technology resources, capabilities and innovation practices across different contextual settings.

The paper is structured in four sections. The first section discusses the theoretical underpinnings to the study, research around the IT capabilities, in order to understand the technology-in-use phenomenon, and the role of IT in innovation practices. It is followed by two sections that address the method applied in this paper and present the results of the study. The final section of the paper covers practical and theoretical implications of the research, including limitations of the study, and then sets the research direction for further studies.

\section{Theoretical background}

\section{Unfolding the technology-in-use process: A capability approach}

In order to address the research objectives, we first need to understand how service firms actually deploy and utilize mobile technology, and if there are any behavioral differences in the ways service firms deploy mobile technology. As stated in the introductory section, previous studies have looked at the impact of mobile technology (Hameed 2003; Jayaram, Manrai, and Manrai 2015) on organizational productivity and performance, albeit with no in- 
depth understanding of how firms utilize mobile technology. Another concern in the extant study on mobile technology is the narrow focus on technicality. The majority of studies on the use of mobile technology focus on the technical nature of mobile devices despite the fact that the dynamic nature of the mobile business environment requires a focus on usability that goes beyond the device itself (Tarasewich, Nickerson, and Warkentin 2002).

To study mobile technology deployment we utilize a capability approach. Originating from the resource-based view (RBV) (Penrose 1959), a capability approach discerns a firm as a bundle of assets and skills and knowledge where capabilities imply the use-in-practice analysis of assets and competence deployment (Day 1994; Song, Di Benedetto, and Nason 2007). Organizational capabilities demonstrate the value or benefits of assets to be used strategically and developed within processes and routines (Day 1994). Furthermore, the capabilities approach contemplates the strategic behavior of a firm in managing and adapting to the environmental context, by taking into account company strengths (Day 1994), and it also focuses on understanding the links and the processes that exist between resources, skills, and information, which eventually lead to the sustainability of competitive advantage (Song, Di Benedetto, and Nason 2007).

According to Song, Di Benedetto, and Nason (2007), technology capabilities and IT capabilities represent two distinct categories of organizational activities. Technology capabilities represent a broader set of processes linked to service/product development, production, and technology-sensing processes, whereas IT capabilities concern the functions for which IT is responsible, such as communication and the cross-functional integration of market information (Song, Di Benedetto, and Nason 2007). Crook and Kumar (1998), on the other hand, take a more integrated approach to defining IT capabilities as "state-of-the-art technology and its use for productive business purposes." The composition of IT capabilities, as with all organizational capabilities, is complex in nature, and although IT infrastructure is 
a main underlying platform of all processes involved in IT utilization, the process of deploying IT infrastructure based on organizational strategy, skills, and knowledge is what establishes the competitiveness of companies (Leonardi 2011). The analytical vision of what IT capabilities a firm possesses can be interpreted and managed on three interdependent levels: (1) resources, comprising IT technical infrastructure and all physical systems, devices, and software support; (2) the organizing level, including co-ordination mechanisms for IT deployment and the skills the firm has available, in order to use IT resources; and (3) enterprise level, which concerns the strategic vision of the organization on the role IT plays in the company (Tarafdar and Gordon 2005; Huang, Li, and Chen 2009). Moreover, the enterprise level of IT capabilities focuses on the benefits and services derived from utilizing in combination a firm's IT 'material agency' (resources) with 'human agency' (employee skills and process management principles) (Huang, Li, and Chen 2009). Hence, understanding IT capabilities facilitates rigorous decision-making regarding investments in purchasing IT resources and acquiring additional skills to employ new IT infrastructure. In addition, a study by Lu and Ramamurthy (2011) found that there is a strong positive relationship between the amount of money a company devotes to purchasing new IT and the superiority of IT capabilities in that company, which eventually leads to IT capability contributing to superior performance.

Several studies on IT capabilities (Bhatt and Grover 2005; Huang, Li, and Chen 2009) underline the significance of this type of capability on both strategic and operational levels. Effectively deploying IT resources and aiming at delivering superior value to customers appears to be a critical issue for many firms (Bharadwaj et al. 2013). Studies by Bharadwaj (2000), Song, Di Benedetto, and Nason (2007) and Chen and Tsou (2007) demonstrate that IT capabilities lead to better financial results for companies, while Song, Di Benedetto, and Nason (2007) found additionally that the proactive use of IT increases financial success in 
organizations. Moreover, Bharadwaj (2000) and Tarafdar and Gordon (2005) conclude that positive relationships between IT capabilities and performance are explained through the greater strategic flexibility companies achieve as a result of IT integration into the generation, dissemination, and exploitation of market data, which eventually allows firms to respond effectively to market needs and sense opportunities for proactive, strategic actions.

Despite the favorable examples mentioned above, several factors may impede the positive impact of IT capabilities. Bharadwaj et al. (2013), for instance, state that stationary desktop IT may prevent companies developing full organizational agility within operational processes, termed 'operational adjustment agility'. The rigidity of fixed IT architectures, including systems, devices, and even software, may impede companies from maintaining superior flexibility in terms of communication and the cross-functional integration of data (Allen and Boynton 1991). Having operational adjustment agility in place means embedding flexibility and proactive response elements in company operations, and such agility forms the basis for translating creative initiatives and innovative ideas into a set of objectives to be implemented within the new product and new service development phases (Lu and Ramamurthy 2011). The findings of Lu and Ramamurthy (2011) further challenge the results of Bharadwaj et al. (2013) by revealing that IT capability has a positive relationship with operational adjustment agility. We reviewed the operationalization of operational adjustment agility and IT capability constructs and realized that Lu and Ramamurthy (2011) tend to view IT capability as a broad category of different technologies that transmit and communicate information, and where mobile technology is logically but not explicitly included. Following studies on business IT use and adoption, and employing a capability approach to explore mobile technology deployment practices and how it affects innovation, would help to understand mobile technology-in-use processes and address the research objectives formulated in the introduction section. 


\section{Innovation practices and information technology}

The classical approach to defining and conceptualizing innovation (Rogers 2010) stipulates that service firms absorb technology passively and therefore cannot be creators of innovative outcomes themselves (Barras 1986). Service firms are no longer passive technology users but do create new ideas and processes that result in superior competitive advantage, thereby allowing such firms to contribute substantially to the economic growth of nations globally (Lusch and Nambisan 2015).

In the service context innovation is a process linked closely to the way service activities operate - within a discontinuous system of interaction among organizational elements such as knowledge, employees' skills, technological competences, strategy, and organizational culture (Clayton 2003; Lusch and Nambisan 2015). Innovation, therefore, is a dynamic process and a complex construct for analysis. While innovation in services has received ample attention from scholars (Edvardsson et al., 2013; O'Cass, Song, and Yuan 2013), no consensus has been reached in regards to its definition.

Past research has not examined the impact that technology adoption and its use have on the innovative outcomes of service firms, such as the reverse product cycle (RPC) model (Barras 1986), which proposes that the process of new service development (NSD) behaves conversely to new product creation in manufacturing firms. Despite these limitations, Den Hertog, Van der Aa, and De Jong (2010) and other scholars (e.g. Gallouj and Weinstein 1997) agree with Barras, in that technology — either in the form of the actual outcome or as a facilitating mechanism in processes - plays a significant role in any innovation production practice, regardless of whether it takes place in a manufacturing and or in a service context. Den Hertog, Van der Aa, and De Jong (2010) suggest that service firms can perform innovation development as proactive technology developers, through how they utilize technology to produce new services, and even develop completely radical technological 
solutions. In fact, real-world practice illustrates that new, radical service creations occur through the deployment of social media platforms (i.e. Facebook, Twitter) and mobile technology, thus leading to the emergence of new industrial players in the sphere of gaming, advertising, construction, and logistics.

The complicated nature of the technological contribution to innovation practices indicates the need to explore organizational processes through the use-in-practice perspective. Using the use-in-practice perspective, Chen and Tsou $(2007 ; 2012)$, key authors in the field of studying the link between IT capability and service innovation practices, found that service firms' IT capability enables various innovation practices in the form of improved or radical service offerings and processes. Chen and Tsou (2007) also defined service innovation as the practices of adopting, initiating, and implementing new processes, new ideas, and new activities. Innovation comprises ongoing and procedural practices rather than just a set of innovative outcomes visible in tangible elements, and service innovation practices are divided into two categories, namely service innovation practices in process and service innovation practices in product. Process service innovation practices refer to service innovation practices in customer-related process activities such as customer information inquiry processes, customer experience management and consultation activities, selling, and after-sales activities, and it represents new approaches to the functioning of many processes and activities in a more effective, improved, or completely new way. Chen and Tsou (2012) and Lusch and Nambisan (2015) recommend focusing on the resource structure of service firms, where strategic and operational changes in resources composition might result in process service innovation practices. Product service innovation practices, on the other hand, is concerned with degrees of innovation and the categorization of innovation outcomes (Gallouj and Weinstein 1997), particularly improvements or positive changes in service 
offerings, for instance modifications in service product features such as packaging and design, or creating a new line of service.

Chen and Tsou (2007; 2012) approach the question of what role IT plays in SIPs employing the survey method to test and measure product service innovation practices and process service innovation practices constructs, whereby a set of statements representing activities for each practice is presented and respondents have to choose whether their company is involved in such activities. In our point of view, the outcomes of such testing are limited with inability to capture ad hoc cases of service innovation practices. Hence, empirical research that is exploratory in nature is required before attempting to measure statistically the impact of IT on innovation in service firms. Aiming to take a holistic perspective on innovation in the service context, our study employs Chen, Tsou, and Ching's (2011, pp. 1334-1335) view that "service innovation... captures both the development of new service offerings and the processes or methods employed." The above categorization of service innovation practices by Chen and Tsou (2007) provides semantic direction for our study to explore innovation practices in service firms.

On the other hand, extant studies (Rogers 2010; Stadler 2011) prove that IT channels facilitate the development and diffusion of new value in processes and as products, irrespective of whether it is a manufacturing or a service firm. IT resources have been identified as a critical element in firm competitiveness across industries (Leonardi 2011). However, the diversity of technological solutions and infrastructures tends to be masked under a single conceptual title — 'information technologies' — which is a metaphorical assumption that stationary desktop IT and technological artifacts, with the embedded ubiquity and mobility features that allow communication, value creation, and delivery within space and time-independent contexts, belong to the same category of technologies and as a result lead to the same benefits for users (Tarasewich, Nickerson, and Warkentin 2002). 
Tarasewich, Nickerson, and Warkentin (2002) argue that the technical nature of all existing IT, including mobile technology, has an evolving character through incessant incremental modifications and the introduction of radically new solutions in the form of devices, networks, and protocols. Hence, mobile devices simply offer an alternative way to engage with a traditional website, independently of time and space.

A growing number of researchers (Feijóo et al. 2009; Jayaram, Manrai, and Manrai 2015) believe that although all IT possesses common technical capabilities, such as task automation, the real-time transmission of data, and proactive communication, meaning that stationary IT shares ubiquitous characteristics with mobile technology, the dimension of mobility facilitates an entirely new approach to product and process development, which is fundamentally different to other IT practices in the manufacturing and service sectors. Liang et al. (2007) argue that mobility facilitates higher efficiency and improved performance in a different manner from other stationary types of IT. To the best of our knowledge, no currently published studies have explored whether mobile technology is a driver of organizational innovation (i.e. process setting) and a tool for introducing new products and solutions to the market (i.e. product setting). This gap is addressed through the main purpose of this study, i.e. to explore whether mobile technology deployment affects service innovation practices.

Innovation is prioritized by many firms aiming at achieving and sustaining competitive superiority. The classical approach to defining and conceptualising innovation views manufacturing firms as the only locus of innovation, where technological competence is considered to be a priority within the resource portfolio and the major stimulus of new value creation (Rogers 2010). The classical definition of innovation focuses purely on technology applied more to the product setting. However, the integrated approach expands this definition by including the process setting (Lusch and Nambisan 2015; Schaarschmidt, Walsh, and 
Evanschitzky 2018). This is particularly key in creative firms delivering business-to-business services, as innovation activities involve adding new and enhancing existing services, all of which are termed 'innovation practices' (Berry et al. 2006; Chen and Tsou 2007). Studies adopting an integrated approach on innovation are quite fragmented and mostly conceptual in nature (Schaarschmidt, Walsh, and Evanschitzky 2018). Thus, further studies on service innovation practices, employing an integrated view to study both the product and process settings, are critical (Chen and Tsou 2012).

A facilitating role of information technologies in stimulating innovation practices is a wellestablished fact (Chen and Tsou 2007; 2012). A new wave in a technological evolution, namely mobile technology, has been neglected as a distinctive technology, as it has been masked under the single conceptual title "information technologies" (IT) (Bolat 2016; Bolat, Kooli and Wright 2016). Existing studies (Hameed 2003; Jayaram, Manrai, and Manrai 2015) have found that mobile technology provides a quick response to market needs, thereby enabling competitive advantage for firms deploying such technology. Nevertheless,

\section{Methodology}

In order to address the two research objectives we employed the evolved grounded theory approach (Corbin and Strauss 1990), where initial theoretical presumptions ground and direct a profound exploratory process. Existing IT studies (Crook and Kumar 1998; Leahmann and Fernandez 2007) which adopt the grounded theory method argue that Corbin and Strauss's (1990) approach proposes a set of systematic procedures to locate the focus and then analyze findings.

In order to maintain theoretical consistency we adopt the practice perspective on service innovation conceptualization, as proposed by Chen and Tsou (2007; 2012), according to which service innovation is a phenomenon of a procedural, ongoing, and complex nature 
where two sets of practices might emerge, namely product service innovation practices and process innovation practices.

\section{Data collection}

Contextually this study focuses on a "hotbed for new ideas and commercialisation," i.e. the creative sector (Handke 2007). Creative businesses occupy a top position in the expansion of mobile technology's benefits, particularly (Feijóo et al. 2009) through the emergence of new players, including advertising firms specializing in mobile advertising content creation. In fact, the creative sector is home to pioneers and advanced adopters of digital technologies (Fleischmann, Daniel, and Welters 2017).

Using secondary sources and publicly available directories for creative service industries, we constructed a database of 75 creative agencies, containing general information on each business such as an overview of business services, employee numbers, and contact information. Furthermore, all 75 agencies were contacted via e-mail or phone and asked if their organizations use mobile technology for internal and product/service development purposes. Thirty-one agencies responded, from which 28 agencies reported using mobile technology in their daily operational activities as well as for strategic business purposes and four agencies responded as not using mobile technology. These four agencies were included as negative cases to complement, interpret and compare stories of positive 28 cases. All 31 creative agencies represent the UK advertising and marketing industry based in London (two firms), Hampshire (four firms), Sussex (two firms), Somerset (one firm), West Midlands (one firm), and the majority (twenty-two firms) in Dorset, due to the geographical proximity and therefore convenience - of us for conducting face-to-face interviews. Table 1 provides the overview of the sample.

[Insert Table1] 
Micro-entities prevail in our sample, as 17 agencies employ up to ten employees only. Nine agencies are considered 'small', with up to 50 employees, and five agencies are 'mediumsized' and operate with up to 200 employees. The participating creative businesses offer their business clients a range of services, including traditional print advertising, consultancy solutions such as market research, branding, and strategic marketing, and, finally, digital marketing solutions. The nature of the processes in all 31 agencies is project-based, where each new project is assigned to a new account manager, depending on the client's objectives for each task.

We conducted 31 semi-structured, in-depth, face-to-face and web-based interviews with key decision-makers in each creative business employing mobile technology (see Table 2 for the detailed profile of the sample). Most interviewees own their businesses independently (13 out of 31 interviewees), nine out of 31 interviewees are part-owners of their firms. From the owners and part-owners interviewed in this study, the majority of the interviewees are responsible for managing the whole business (12 out of 22 owners and part-owners), four independent business owners are freelancers, five interviewees have responsibilities of Creative Director and one interviewee calls herself a Marketing Director specifying that her husband/partner manages the business overall (agency 11). Agency 11 is not the only familyowned business in the sample. Agency 10 is also a family-owned business where interviewee, son of the business owners, is responsible for managing business development. In addition, a few other interviewees are responsible for a particular area within a business devoted to understanding technological advancements. We interviewed a marketing director in one of the agencies (agency 6), an account manager (agency 24), three new media/digital directors (agencies 1, 12, and 18) and three strategic directors (agencies 14, 16, and 21). All 31 interviewees represent a homogeneous group based on the fact that they are all key decisionmakers in respect to mobile technology deployment in their agencies; they are all 
knowledgeable about mobile technology deployment on both strategic and operational levels and about service innovation practices in their creative agencies.

Each interview lasted from 40 minutes to one-and-a-half hours. We asked the respondents about strategic business direction and the use of digital technologies, through questions either derived from the existing literature (Chen and Tsou 2007; 2012) or adopted and modified from Dutta et al.'s (2003) study exploring the pricing process as a capability. Although an inductive research scenario predetermines key research themes and guides the exploratory process, we nevertheless remained open to the discussion of any emerging issues. In addition to interview transcripts and memos, secondary documentation (information available on firms' websites and social networking sites such as LinkedIn, Twitter, and Facebook) added to the body of information on mobile technology deployment projects and processes in participating agencies. In addition, we maintained further e-mail communication with the interviewees and used technical documentation provided by the respondents. Technical documentation includes project-management guidelines, internal reports for mobile technology-related projects, and agencies' credential reports.

\section{Data analysis}

Employing grounded theory procedures (Corbin and Strauss 1990), we analyze and extract patterns illustrating differences and similarities across and within multiple cases, in an attempt to construct a conceptual model. We use simultaneous data collection and analysis to maintain a constant comparison approach that allows for the further refinement and specification of the research instrument and builds a rigorous theoretical conceptualization of the concepts in question (Corbin and Strauss 1990). Primary data, mainly interview transcripts, were exposed to data reduction through the three-stage coding procedures.

The first stage, open coding, transforms the empirical data from individual accounts to crosspopulation accounts with references grouped around key topics. We worked through each of 
the interview transcripts and employed line-by-line coding to take references around topics and main research objects. Firstly, textual elements such as words, sentences, phrases and paragraphs were analysed to discover and highlight attitudes, incidents (experiences), actions and results of actions (outcomes). These units of information were found by looking for adjectives and transitive (action) verbs. To label concepts, in most cases we used transitive (action) words to reflect on the nature of the research objects. Action concepts in comparison to noun concepts are more suitable for describing a process (Partington 2000). Moreover, according to Denzin and Lincoln (2011) action concepts simplify the identification of patterns phase during the data analysis because issues are addressed dynamically meaning that interviewees mostly discuss process activities rather than illustrate static phenomena. Examples of labels for the action concepts include 'managing projects', 'communicating' and 'researching'. As a matter of fact, where appropriate, we used directly quoted words to label concepts, a few examples of which are 'managing project', 'teleworking' and 'experimenting'. Overall, some concepts were labeled very close to the interviewees' accounts and other concepts had more abstract labels. In addition, we followed Martin and Turner's (1986) advice on being flexible during the analysis process, in particular one or more concepts was recorded for a single incident, action or outcome, which in turn supported the process of finding linkages and relationships between concepts. After a line-by-line coding of the first four interviews was completed, the comparative method of grounded theory was adopted to support line-by-line coding of all subsequent interview transcripts. In particular, units of information were examined for similarities and differences between the interviewees' claims. Each concept was then keyed into the NVivo 10 software. The crosscomparative analysis identified some standalone concepts but where strong similarities between individual concepts were found these concepts were treated as sub-concepts and were grouped to represent a more general concept. In this study general concepts are labeled 
as theoretical concepts because they represent abstract meanings and are foundation in building a theoretical conclusions. Overall 50 theoretical concepts emerged after open coding process. Each of these 50 concepts was considered as a potential category to be explained and examined in the second stage of coding - axial coding. Table 2 lists the theoretical concepts and illustrates how representative the theoretical concepts are across the sample. Overall data analysis included the profile concepts, which helped to identify and examine diverse practices in deploying mobile technology.

\section{[Insert Table 2]}

Implementation of the axial coding, moving between inductive and deductive thinking, involved two phases, categories' identification and categories' refinement. Categories were identified and created by comparing the initial theoretical concepts. Where similarities between theoretical concepts were found, meaning group of concepts appeared to relate to the same phenomenon, a category was identified. For example, in integration mobile technology hardware and mobile technology software represent a mobile technology infrastructure, a mobile technology resource that a firm has and works with. However, additional concepts such as mobile technology skills, internal social and external business networks and relationship and all concepts related to organizational culture were identified to represent a single category entitled 'mobile technology resources'. Categories' refinement was conducted by cross-comparison of interviewees' views, meanings, incidents and actions concerning a single event, the process of deploying mobile technology in creative agencies delivering marketing, advertising, digital architecture and digital design services. We reflected on coding density in terms of the number of text elements referenced under the integrated category or sub-category. However the main emphasis was on examining the number of sources wherein the integrated category was detected - to understand how widely particular views were held across the sample. Categories' refinement focused on 
understanding relationships and interactions between theoretical concepts. The final stage, selective coding, aims to explain the data by integrating categories, derived from axial coding, into core categories (theoretical constructs) and completing the grounding process by linking core categories (Corbin and Strauss 1990). Selective coding assumes that not all categories are equally important or relevant for the theoretical conclusions. In this study core categories, identification of which is based on the impact level (the highest number of references and greatest frequency of categories' representation within the data), are interrelated to explain the role of mobile technology deployment in creative businesses' innovation practices.

\section{Findings and Discussion}

The results of our research are presented as answers to the two search objectives we set previously and discussed simultaneously against existing research. The first section addresses RO1. We also discuss three clusters of creative businesses derived from a cross-firm comparative analysis of mobile technology deployment practices (RO1 and RO2). Each of 28 agencies that deploy mobile technology belongs to one of three mobile technology deployment clusters. The second section addresses the research purpose of this paper (RO2) by discussing and reflecting on whether and how mobile technology deployment affects service innovation practices within each mobile technology deployment cluster.

\section{Mobile technology deployment process}

Results from 28 out of 31 interviewed agencies shape our understanding on how interviewed firms deploy mobile technology and what capabilities are critical to its deployment. Four categories represent the process of mobile technology deployment, namely mobile technology resources, mobile technology deployment activities, mobile technology deployment routines and mobile technology capabilities. All 28 interviewees, who responded 
positively to the extensive deployment of mobile technology in their business, are consistent in their views on each of these four categories. In addition, three out of 31 interviewees $(2,15$ and 26) saw no value in the deployment of mobile technology within the business context. However, the overall discussion of each category classified under the process of mobile technology deployment reflects on these negative views.

The data analysis approach, in this case evolved grounded theory, facilitated the emergence of two core categories emphasized by all studied firms and which characterize mobile technology deployment (see Table 4). Consistency amongst the responses is presented under the column entitled 'Sources'.

\section{[Insert Table 3]}

\section{$\underline{\text { Mobile technology resources }}$}

Interviewees from 28 creative agencies deploying mobile technology prioritise the role of mobile technology resources in driving new ways of exploiting it accordingly. The 'mobile technology resources' category constitutes a complex interactive system of sub-categories, which are tangible (physical) and intangible (organisational culture and human capital) resources. Physical resources in the form of mobile technology hardware and software establish a firm's mobile technology infrastructure (MTI) and represent the only tangible type of asset associated with mobile technology deployment. All 28 agencies that deploy mobile technology stress the importance of MTI in the form of hardware and software. In other words, MTI integrates various mobile technology categories used by a business. MTI was consistently presented as a strategically important aspect of the organizational decisionmaking across all the studied firms. The managing director of firm 2 particularly communicated that their company transformed its "software in-house within the last two years," to keep up with the pace of technological changes across global business. 
Number of studies explore the use and adoption of mobile technology by SMEs (Quigley, McRobbie, and Watt 2012; Heilig and Vob 2015; Jayaram, Manrai, and Manrai 2017). However, the only consistent results across these studies and this that is that SMEs favour mobile technology deployment due to a low cost of MTI and a low cost of maintaining the systems and integration across the firm. In this study we found that mobile technology are indeed low cost resources; however, creative agencies tend to heavily invest in establishing advanced systems, purchasing sophisticated software to deliver unique and innovative solutions to their business-to-business clients. This perhaps due to ubiquitous opportunities presented by mobile technology accessing the Internet and data (Lichtenthal and Eliaz 2003). Secondly, two types of resources shape a business' human capital - essential to mobile technology deployment: mobile technology skills and expertise represent an intangible knowledge base, which can be used to create mobile technology infrastructure; and business networks and relationships, both within and outside the firm. Studies on fixed networks and stationary desktop IT used in an organizational context (Huang et al. 2006; Wang et al. 2012; Ong and Chen 2014) illustrate similarities between MTI and fixed networks and stationary desktop IT in a cost-effective way, to improve operational processes and the importance of external consultants and partnerships in accessing required IT systems, hardware and software.

The results of the exploratory study demonstrate that having tangible mobile technology resources in the form of MTI is not sufficient to maximise the use of mobile technology to its full potential. A complementary organisational system of beliefs and behavioural norms is found to facilitate and guide mobile technology deployment as well as having a particular MTI investment strategy. No existing research in relation to mobile technology deployment describes the composition of mobile technology resources as an interactive system of skills, relationships, MTI and organizational culture. Nevertheless, applying RBV as a theoretical 
basis, studies on fixed networks and stationary desktop IT identify similar groups of resources to form an overall bundle of IT resources (Chen and Tsou 2012; Wang et al. 2012; Bharadwaj et al. 2013; Ong and Chen 2014), with the exception of organizational culture. Organizational culture either complements IT resources (Zhang and Tansuhaj 2007) or it is referred to by a different conceptual name. Thus, Wade and Hulland (2004) refer to organizational culture as a system of information systems, planning and change management practices and market responsiveness. On the other hand, Wang, $\mathrm{Hu}$ and $\mathrm{Hu}$ (2013) label organizational culture that grounds the process of fixed networks and stationary desktop IT deployment as a 'governance mechanism' which leads and manages the use of IT resources. In this study interviewees whose agencies extensively deploy mobile technology identify four behavioural orientations and settings that accompany mobile technology deployment continuous learning, technology embracing, focusing on clients' needs and the flexible and adaptive process of creative thinking and responding to the external environment. Interviewees from all 28 agencies deploying mobile technology cite "learning culture as a key" [I8; I31], significant aspect of mobile technology deployment, by linking it to the exploration of opportunities made possible by mobile technology deployment and how this technology can be potentially utilized. Interviewed agencies also continuously analyze technological trends and explore ways of exploiting mobile technology. Hence, technological orientation is a foundation of individual attitudes towards embracing technology (the extent of embracing technological orientation) and seeing the value and potential in integrating technology into processes and services. All agencies interviewed in this study employ project-oriented processes where resource allocation, skills requirements and outcome specifications depend on each client's objectives and needs. The twenty-five creative agencies (except firms 20, 22 and 24) that deploy mobile technology also place emphasis on clients' requirements and then sell them bespoke solutions. These businesses prioritise and 
engage in responding to customers' current needs but see clients' objectives and constraints as limitations to creative thinking. According to interviewees 25 and 12, most of the projects "are guided by clients' budgets" [125] and "the whole process is based on clients' requirements, which are objectives for us to achieve so that we all are very clear in terms of what we are doing" [I12]. "Some companies already come to me with the content in mind that they want, so it makes my work a lot easier," adds interviewee 25 . Finally, 18 agencies $(1,3-$ $5,7,12-14,16-19,21,25,27-30)$, which deploy mobile technology extensively, stress that mobile technology deployment makes the process of creative thinking adaptive and enables reactive and proactive (the mode of embracing adhocracy) responses to the external environment.

\section{Mobile technology capabilities}

According to our interviewees, technological resources itself, without unique ways of exploiting, transforming or reconfiguring it, does not create or deliver any value. In line with Jones, Macpherson, and Jayawarna's (2014, p. 142) claim that "resource alone is not source of value," this study illustrates that what matters is the deployment of resources. Creative business practitioners view mobile technology capabilities as unique practices of business utilizing mobile technology resources to create competitive advantage. Strangely, when defining mobile technology capabilities, the interviewees articulated their views in line with Day's (1994) conceptualisation: a capability implies the ability to combine resources and competences and then deploy them advantageously. No currently published research has introduced the concept of mobile technology capabilities.

Mobile technology resources are part of mobile technology capabilities, because they represent tools for effective learning and creativity. This finding corresponds with the second group of IT research scholars (Wade and Hulland 2004; Wang et al. 2012; Chen et al. 2015), who define IT capabilities as "a firm's ability to mobilise and deploy IT resources effectively 
to perform" (Wang et al. 2012, p. 329) activities such as strategic IT planning, information system development, leveraging and the use of information systems and the management of IT functions and IT assets. In line with this conceptualisation, we identified five mobile technology capabilities: (1) reconfiguration and the effective use of mobile technology resources, (2) the transformation of existing processes, service offering and in some instances an organisational business model, (3) learning capability distinct from learning orientation as part of organisational culture, because learning capability involves the improvement and modernisation of solutions offered to clients, (4) solving clients' problems that require contextual and non-systematic measures and (5) strategic leadership capability to facilitate and drive the successful deployment of mobile technology.

Leveraging includes accessing mobile technology capabilities not only through acquisition, accumulation and outsourcing but also via the orchestration of mobile technology resources to create a unique combination of organisational resources. For instance, in relation to MTI, 28 creative agencies deploying mobile technology have different ways of gaining access to the required mobile technology hardware and software. Some agencies (I3, I2, I14, I18) invest heavily in building their own MTI and view it as a strategic priority:

"We have changed our own software in-house within the last two years to align it with current mobile application technologies. We are looking all the time at that to see how we can best leverage what it offers a business like ours... We purchase new devices as soon as they come to the market... For us as a company mobile technology is definitely a strategic resource." [I3]

All studies that define IT capabilities as a bundle of various IT-related resources imply that IT capabilities include the ability to reconfigure and acquire IT resources. This study explains this point further by adding that leveraging can be done through the acquisition, accumulation and outsourcing of mobile technology resources. Differences could be explained by the 
contextual setting of the study, SMEs in particular. Bayrak (2013) identified relationships between a small size of the firms and different practices to build IT infrastructure emphasising that outsourcing is the common way to leverage IT resources. Based on the available investments, SMEs tend to maker different decisions regarding establishing the firm's resource base.

All creative business practitioners participating in this study agreed that mobile technology deployment does not really create new processes but instead transforms existing activities. Communication, project management, service delivery and development are areas that mobile technology helps to change, resulting in efficiency, strategic and operational flexibility, operational productivity and cost efficiency. In addition, mobile technology deployment enables improvements to service offerings through the modification of existing services (mobile technology as a new channel to deliver existing services) or the introduction of new and radical services (mobile applications, mobile games). The transformation of processes through the integration of IT into operational processes is a well-known fact (Huang and Chen 2009; Lu and Ramamurthy 2011; Bharadwaj et al. 2013; Ong and Chen 2013; Chae, Koh, and Prybutok 2014; Chen et al. 2015). It is also listed by Nguyen, Newby, and Macaulay (2015) as one the important reasons SMEs adopt IT. Mobile technology, however, takes the transformation of processes; products or service portfolios and business models to a different level in comparison to fixed networks and stationary IT. The difference lies in the distinctive nature of mobile technology, whereby mobility enables ubiquitous work but mostly importantly work on the go.

Apart from learning being a foundation for organisational culture in agencies that deploy mobile technology, it is a complex capability that firms exercise when deploying mobile technology: 
"If we need to learn to do something new, the ability to offer a new service will mean for us having to learn how mobile technologies are consumed and whether it might be a good channel to get what the client wants. So analysing the whole chain from clients' needs to their customers' needs is common practice." [I10]

Wang et al. (2012) stress the value of learning in IT deployment. Andreu and Ciborra (1996) add that learning facilitates the integration of IT resources into organisational processes and activities. This study finds that in order to transform business and lead to competitive advantage, mobile technology resources can be effectively leveraged and creatively spanned by establishing learning orientation as part of organisational culture as well as through a learning capability that integrates scanning knowledge into the external environment, acquiring knowledge externally and internally, assimilating knowledge through formal and informal sharing mechanisms and using new knowledge to transform processes or develop new services. In fact, Calantone, Cavusgil, and Zhao (2002) stress that learning orientation is a foundation to building a firm's innovation capability. Hamburg and O'Brien (2014) show the similar results within the context of SMEs.

Client orientation underpins the strategic direction of all 28 firms that deploy mobile technology, in order to provide bespoke solutions to clients' problems. The managing director from firm 9 comments:

"We started thinking about offering location-based mobile marketing as a result of our clients coming to us and asking us to resolve a problem through traditional sales promotion marketing."

Last, agencies explored in this study are mainly small in size, so leadership and entrepreneurial spirit have an enormous impact on business strategy and the way processes are organised. In particular, the entrepreneurial vision to prioritise technology as a strategic business resource and to embrace the latest technological trends impacts on employee 
behaviour and the way they work. Most of the managing directors and business owners who participated in this study are passionate about mobile technology, receptive to technological tends and drive the deployment of mobile technology in their business. Feeny and Willcocks' (1998) study emphasises leadership and managerial competences as key to exploiting IT resources. In particular, they highlight the strategic vision to align IT with organisational strategy and abilities, to manage relationships effectively within teams. Strategic vision is important in this study, too. But the strategic vision is this study is mostly related to the context of SMEs - the vision of the business owner to adopt IT (Elbeltagi et al. 2013). However, the results of this study indicate that when it comes to mobile technology deployment, leadership is not limited to the power of a single individual. As a result, small firms develop multiple intrapreneurial identities (Menzel, Aaltio, and Ulijn 2007) rather than restricting organisational leadership in entrepreneurial identity's (owner-manager's) hands (Elbeltagi et al. 2013). Flexible mobile working, enhanced communication processes and continuously developing MTI enable and simultaneously force individuals to lead projects as well as interchange roles and responsibilities. In fact, such an attitude to coordinating process of mobile technology deployment results in mobile technology skills being transferred across the firm.

\section{Diverse practices in deploying mobile technology: the cluster analysis}

The participating agencies are clustered based on three strategic but in essence behavioural approaches to mobile technology deployment, using dimensions of mobile technology resources and mobile technology capabilities and profile characteristics of each firm (see Table 5).

\section{[Insert Table 4]}

Three clusters exhibit three distinctive patterns and practices regarding the deployment of mobile technology. However, within each individual cluster, creative agencies follow similar 
patterns in deploying mobile technology and exercising mobile technology capabilities. Cluster A has agencies that plan and organise mobile technology deployment on an operational level only. Businesses that see mobile technology as an operation-enabling tool do not strategically change their business processes but adapt mobile technology deployment practices to the existing strategic direction of the firm. Hence, only the operational process is transformed. Cluster A agencies are followers in their behavioural attitude towards mobile technology deployment in the sense that they "find, track and analyse" the competition, because, according to interviewee 6 , the media-focused nature of creative businesses implies "taking advantage of all different technologies." As a slight aside, all 28 agencies from the three clusters stress the significance of learning (researching and scanning for opportunities in particular) as part of the mobile technology capabilities set.

Agencies in Cluster B demonstrate that there is a possibility to diversify the strategic orientation of the firm and work on specific mobile technology deployment projects (transforming services). Strategically, such projects are aligned with the overall business strategy. Agencies representing Cluster B react to mobile technology deployment by calling it an 'adaptive corporate culture' whilst balancing it with the existing business profile:

"Any good company will always be open to adapting to its surroundings. The only thing constant due to technology advancements is change.... You have to change with the landscape. We do change with the landscape. Not change completely, but we adapt, become flexible, keep a balance. This is our corporate culture." [I1]

Creativity has a central role in the adaptation processes of agencies that are part of Cluster B and allows them to challenge and transform existing mobile solutions and applications in the market. This then helps them to advance the mobile technology deployment process and to bring new revenue streams into the company. 
Finally, one group of creative agencies sees the opportunities mobile technology triggers as an area for entrepreneurial spirit and the chance to take a risk in transforming the business model of the company to one specialising in mobile technology's digital offering (Cluster C). The managing director of agency 3, which is categorised in Cluster $\mathrm{C}$, states that the "identification of unique competences that mobile technology possesses" induced them "to restructure, even start-up from the scratch" their business. Cluster C creative businesses take up a leading role in embracing mobile technology innovatively and creatively. It is clearly evident that the third strategic behavioural pattern towards mobile technology deployment implies the development and delivery of innovative service solutions.

Number of studies explores the use and adoption of mobile technology by SMEs (Quigley, McRobbie, and Watt 2012; Heilig and Vob 2015; Jayaram, Manrai, and Manrai 2015). However, the only consistent results across these studies and this paper is that SMEs favour mobile technology deployment due to a low cost of mobile technology categories and a low cost of maintaining the systems and integration across the firm. This study shows that mobile technology are indeed low cost resources; however, some creative agencies tend to heavily invest in establishing advanced systems, purchasing sophisticated software to deliver unique and innovative solutions to their clients.

\section{Link between mobile technology deployment and innovation practices}

In order to address the main aim of this study (RO2), i.e. to explore the role of mobile technology deployment in service innovation practice in creative businesses, we use the knowledge we generated from exploring mobile technology deployment processes. Therefore, all results are discussed in the light of the three clusters we identified in the previous section.

Due to the chosen conceptualization of innovation in services as a practice, we wanted to see whether theoretical definitions of service innovation practices are in line with empirical 
interpretations of the terms process service innovation practices and product service innovation practices. Interestingly, interviewees conclude that process innovation is a firmspecific concept and product innovation - a client-specific concept. Cluster A agencies reject the idea that, in the context of services, companies deal with product service innovation practices at all. Agency 5's representative stated, "I do not think it is something to do with the business of servicing."

However, creative businesses representing cluster A clearly emphasize product innovation practices, by stating that 'service innovation' and 'process innovation' are interchangeable terms. The marketing director from agency 5 , for instance, said that she would "actually redefine service innovation to process innovation, because this is what servicing is all aboutabout the process."

Clusters B and $\mathrm{C}$ see the difference in two service innovation practices and provide examples for each in their firms. Process service innovation practice:

Service innovation internally is what we are working on all the time, trying to make our processes more organized and more efficient. [I6, Cluster B]

Product service innovation practice:

Product innovation in services is the actual service outcome that the client has asked for but novel, unique, or different... Mobile applications that we have started to produce and now offer on a regular basis to our client are an example. [I2, Cluster C]

Going back to the main purpose of this paper, we question whether the use of mobile technology affects service innovation practice in creative businesses. Collectively, the interviewees believe that mobile technology deployment can facilitate service innovation and stimulate innovation. In fact interviewee 28 notes, "mobile technology stimulates and facilitates service innovation." 
In a number of publications, Chen and Tsou $(2007 ; 2012)$ discover that deploying fixed networks and stationary IT, particularly in the form of IT resources (comprising IT infrastructure, knowledge, relationships and business experience), positively affects service innovation practices. The results of this paper correspond with the IT literature and conclude that mobile technology deployment stimulates and facilitates service innovation by changing processes used in delivering and developing services as well as being part of new service outcomes. Firstly, the stimulation of service innovation implies the indirect role of mobile technology in producing innovative practices. This indirect relationship is the result of changes to and the transformation of organisational processes caused by mobile technology deployment. In support of this argument, interviewee 17 states:

"Mobile technology enables us to do things easier or quicker or differently for clients. I am not too sure if it is really an innovation. But mobile technologies like Dropbox or email or Twitter, as a way of stimulating creativity within the company, drive innovation."

The interviewees particularly address the indirect role of mobile technology in enabling creativity. Interviewees 30 , who view mobile technology as a platform that triggers creative thinking and learning, states:

"Surely, mobile devices stimulate innovative practices, because they are tools to improve our daily routines and be efficient so time is left for extra creativity. " [I30]

Moreover, interviewee 6 adds that generating knowledge about mobile technology stimulates thinking about different ways to "integrate different social and technological opportunities," while operational flexibility enabled through mobile technology deployment "provides a quicker reaction" to solving clients' problems. Hence, practicing learning as part of mobile technology deployment stimulates innovation in services. 
Secondly, mobile technology deployment can play a direct role in facilitating service innovation. In contrast to stimulation, facilitation implies that mobile technology is an input into the innovation process or the outcome. A simple example of mobile technology facilitating service innovation can be found in the introduction of mobile text-based advertising, where mobile technology facilitates the extension of the existing service portfolio by offering a new "delivery channel for the information or a product itself" [I25]. Interviewee 3 talks about a new approach to serving their medical clients, known as CLM (closed-loop marketing). This approach allows pharmaceutical distributors and sales agents to visit General Practitioners and to demonstrate new products by using mobile tablet computers, taking on comments and feedback and then sharing these immediately with the main office. Mobile technology in this example enables one-on-one marketing and efficient data interchange, both of which underpin this new marketing approach. The mobile device is a direct input into developing a new practice and service.

The strategic manager from agency 1 and the managing director from agency 30 clearly identify mobile technology as a tool for improving processes, which eventually leads to innovative practices. Hence, mobile technology itself becomes a critical element of innovative practices:

"With new technology, innovating becomes easier because there is another tool which people can use. It is new, so it allows people to do things differently to how it has been done before. With mobile technology there are new tools now, new ingredients to add to things, making things a bit better, I think." [I1]

As evident from all of the quotes illustrated above, stimulation through creative thinking and facilitation leads to both service innovation practices, namely process innovation and product innovation. However, the three clusters of firms identified in the previous sub-section show differences across service innovation practices. 
Cluster A, which deploys mobile technology on an operational level only, develops innovation through processes but does not produce product innovation as a result of deploying mobile technology. In fact all 28 creative agencies that deploy mobile technology agree that learning as part of mobile technology capabilities stimulates process innovation and even more interestingly in areas such as customer communication and consultation, promotional activities and internal administration and management processes. This is found to be true for all three clusters. Researching the market as part of learning practice particularly supports improvements in areas such as communication and consultation with clusters, service development and service delivery. To support this claim, the managing director from firm 8 states:

"I have the ability to engage in research, no matter where I am. I can create research immediately, because resources are available immediately which allow me to do that. I can advance my client's problem solution simply by having mobile technology."

In addition, the above-mentioned quote indicates that the problem-solving capability also helps creative agencies to innovate within the customer communications, service delivery and development areas. As a result, based on what interviewee 16 representing Cluster C says, researching and understanding the linkages between market behaviour and the opportunity to think about benefits for the client - thereby solving the client's problems - result in new approaches to delivering existing services (content) or new approaches to developing and improving said services:

"One example is $Q R$ codes and the mobile incorporation of $Q R$ readers. We do it and started to work on it when a client approached us with a problem regarding maximising the use of different traditional and digital channels. $Q R$ is prevalent in laptops as well, but if you are out on the street it is not that practical. What we came up with is aligning static media with a mobile that will take you through to content. So 
now a lot of our outdoor advertising is linked with $Q R$ codes, which will take you through to a piece of content, which then extends user journeys. That is really important to keep you engaged with brands. We did a lot of research around this area before deciding that $Q R$ is something we will use to deliver promotional messages or to incorporate into marketing tools we currently use."

Transforming capability is perhaps the key contributor to any process innovation activity. As presented in the subsection, mobile technology deployment allows for the transforming of organisational processes, resulting in "increased productivity" [I13], "improved and efficient process of organising workflow" [I5], "improvements in communication with staff, relationship maintenance and the organising of databases and the interchange of documentation" [I4]. Overall, mobile technology deployment leads to "flexibility in operations" and "quicker reactions" in agencies 6, 8, 9, 22 and 31. However, particularly in Cluster A, mobile technology takes on an operational role and improves processes in internal and external areas, particularly clients' communication and administration, project management activities and developing promotional campaigns for clients and the firm's own branding.

Firms representing Cluster $\mathrm{C}$ extend the impact of the transforming capability to radical changes in organisational structure through the creation of new business divisions or the complete reorganisation of business models. The mobilisation of processes in Cluster $\mathrm{C}$ is not only possible as a result of the transforming capability but also leveraging mobile technology resources. Accordingly, all firms representing Cluster $\mathrm{C}$ operate through databases synchronised and accessible "via mobile devices" [I3]. Firms from Cluster C focus intently on the in-house accumulation and heavy investment in developing mobile technology skills and MTI. Chen and Tsou (2012) found that IT capabilities particularly stimulate process innovation practices. These results are evident in this study on mobile technology 
deployment, where all three clusters are engaged in process innovation practices as a result of deploying mobile technology.

In terms of product service innovation practices, creative agencies representing Cluster A reject the concept of product innovation. However, Clusters B and C clearly indicate that mobile technology deployments have transformed their processes, services and even the overall business model in the case of Cluster C. For agencies representing Cluster B, which challenge the deployment of mobile technology deployment, and Cluster C, which lead the process of embracing mobile technology in SMEs delivering marketing, advertising, digital architecture and digital design services, mobile technology strategically facilitates both process and product innovation. The difference between 'challenging' and 'leading edge' creative agencies relates to the intensity of how mobile technology deployment drives product innovation. Discerning mobile technology as a strategic resource clearly has a basis for product service innovation practice. Hence, leadership is critical in producing product innovation. In agency 1, representing Cluster B's mobile technology deployment, specific strategic options help in viewing mobile technology as a new type of service. Mobile technology is not simply another delivery and interaction channel, as in case of process innovation. Thus, designing a mobile website, for instance, is not purely a transformation of traditional website content into a mobile format, but it is rather a different product which requires different content and even a different set of objectives. Information given by interviewee 3 (Cluster C) corresponds with Cluster B's results:

"Innovation for our firm happens when we have taken an aged or existing system and made it available to our clients on a mobile platform. But then this requires the transformation of content, too."

All Cluster B agencies create mobile websites for clients, not as part of their conventional website design and development solutions but as a separate type of service. For instance, 
agency 7 has several clients asking them to develop mobile websites, because these clients want to have a "mobile format for a specific purpose - measuring the click through rate but most importantly understanding the location profile of mobile website visitors." As a consequence of practicing leadership, transforming and solving problems, Cluster B businesses have extended their existing service portfolio.

Creative agencies that are part of Cluster $\mathrm{C}$ adopt a proactive vision in line with mobile technology deployment (leading capability), in an attempt to reformat existing services by developing new ones. As an example, agency 3 has developed a mobile game named 'Parking Perfection'. This decision was based on technological trends, the expansion of mobile content (learning capability) and the firm's initiative to experiment with mobile devices and mobile technology software (learning and leveraging mobile technology resources capabilities). The 'Parking Permission' game is used as a promotional tool for the client to introduce their product, but it is also an interactive platform which gives end-users the ability to create an end-user database integrating location-enabled information, personal interests and personal contact information details. Since its launch, campaigns delivered through the mobile game as well as download rates for the game itself have been extremely successful. As a result, in agency 3, mobile games development has been embedded in the overall portfolio of services.

By maintaining a proactive strategic orientation towards mobile technology deployment, Cluster $\mathrm{C}$ creative agencies have built strong and "innovative capacity to take on existing technologies and platforms in the market, develop and take it on to a next level" [I3], in order to introduce radical solutions to the market. Innovation capacity is built through practicing leveraging mobile technology capabilities (acquisition and accumulation) and learning capabilities (experimentation). 
Overall it is evident that the impact of leveraging mobile technology resources and transforming capabilities on service innovation practices in the creative services sector depends particularly on the degree of organisational commitment a service firm devotes to mobile technology deployment. This commitment is essentially strategic in its nature. The organisational commitment to mobile technology deployment also determines with what innovation practices a firm is going to engage. Chen and Tsou (2007) also discovered that in the financial sector, strategic leaning towards deploying IT underpins the role of IT in stimulating service innovation practices.

\section{Conclusion}

We have discovered three clusters of creative agencies, which reflect on diverse practices of mobile technology deployment and its impact of innovation practices. Mobile technology is in fact a superfood that with the right combination of resources and capabilities delivers strategic benefits for creative business. We conclude that creative agencies deploy mobile technology extensively (RO1), and it is the interaction between mobile technology resources and mobile technology capabilities stimulate and facilitate process and product service innovation practices (RO2). A critical reflection on existing research findings against empirical results explaining mobile technology deployment in creative agencies has demonstrated overlaps and differences in the results. Results on mobile technology deployment overlap with research on fixed networks and stationary IT. However, no previous studies have explored how mechanisms of combining resources with capabilities affect service innovation practices. This study provides such insights, by specifically investigating the interaction between mobile technology resources and mobile technology capabilities and by reflection on practises across creative agencies. In particular distinct clusters have been identified which demonstrate that depending on organizational commitment of creative businesses to mobile technology deployment, interaction between mobile technology 
resources and mobile technology capabilities can lead to both service innovation practices, in particular process service innovation practices only (Cluster A) and both process service innovation practices and products service innovation practices (Clusters B and C).

\section{Theoretical contribution}

This exploratory study contributes to the discipline of innovation by characterizing mobile technology deployment as interaction between mobile technology resources and mobile technology capabilities. The empirical investigation of mobile technology capabilities covers a detailed identification of dimensions sub-capabilities. These sub-capabilities can be practiced in isolation or in combination. In comparison to existing concepts of IT capabilities that simply represent a bundle of IT resources, the mobile technology concept, in line with the theoretical base of the capability approach, imply the orchestration of mobile technology resources. Hence, mobile technology resources complement capabilities rather than act as part of such capabilities. Thus, a business can possess resources, but only capabilities result in operational or strategic improvements. It can be argued that, essentially, no new knowledge is produced. However, no studies have used the capability approach to study mobile technology deployment. Hence, this is in fact a new topic to be addressed through capability theory. In addition, to our knowledge this is the first study to integrate conceptually service innovation and mobile technology deployment by grounding this conceptualisation in empirical setting, which is creative agencies delivering advertising, marketing, digital design and digital architecture services.

\section{Limitations and future research}

Mainly this research has contextual limitations that prevent generalization of results. In particular research findings are specific to the creative agencies delivering marketing and advertising, digital design and digital architecture services. The geographical limitation of this study as a representation of the UK only presents possibilities to conduct a cross-cultural 
study by extending it to other countries with more or less advanced technological infrastructure. Hence, the contextual constraints of this study represent an opportunity for further studies.

Moreover, numerous overlaps with information systems research suggest the applicability of IT measures to operationalize constructs of mobile technology resources and mobile technology deployment. Alternatively, new measures or items can be developed using the traditional Churchill's (Churchill 1979) method for developing marketing constructs.

The data in this study were largely cross-sectional, thereby presenting a snapshot of an individual's opinion at the time. The adoption of different qualitative methods to either conduct a longitudinal study via the grounded theory method, with the aim of developing a process model, or cover a longer span of time via ethnography would help to build even more detailed information on mobile technology deployment and its role in service innovation practices.

\section{Implications for Business Marketing Practice}

Creative agencies are well-known for pioneering technological transformation due its reliance on information and communication technology. Not surprisingly creative businesses are experimenting with mobile technology, but the extend and the scope of mobile technology deployment, and its impact on innovation practices are under explored.

In practice, understanding the mobile technology deployment process is particularly significant for creative business owners and managers who should not ignore the ubiquitous business opportunities deriving from new technological advancements, i.e. mobile technology. In particular, this study reinforces the distinctive nature of mobile technology so that creative agencies can see the real value in embracing mobile technology.

Moreover, mobile technology deployment represents interaction between mobile technology resources and mobile technology capabilities. Each of these categories is multidimensional. 
As a result, creative agencies can map their mobile technology resources by understanding what MTI their firms have, as well as skills, relationships and organizational culture. Recognizing the composition of mobile technology resources in their firms will enable managers to reconsider their strategic and operational commitments towards mobile technology deployment and make relevant changes to the structure of such resources. Mobile technology capabilities also represent a set of practices which can be employed to orchestrate successfully mobile technology resources. Once again, an analysis of current practices in agencies will help their businesses to realize the potential for further improvements.

The discussion above is even more relevant and valuable to practice, considering the clustering of creative agencies based on organizational commitment they have towards mobile technology deployment, depending on which businesses deploy mobile technology as a purely operational tool, produce new solutions or even transform an entire business model. It is vital for businesses to self-assess their mobile technology resources and capabilities and then plan strategic changes, if relevant, to remain competitive.

The empirical results suggest that creative agencies feel pressured to keep up with technological trends. The analytical results demonstrate that, irrespective of the business model or strategy, or even size (from micro to medium range), firms can engage with mobile technology. Different clusters demonstrate various ways to engage with mobile technology. Additionally, this study signals to creative businesses that mobile technology deployment leads directly to process and product service innovation practices. Once again, creative agencies can make the decision as to whether they are only to effectively manage operations in firms through mobile technology deployment or whether they are to perceive mobile technology deployment more strategically and as a result produce new solutions. 


\section{References}

Allen, B. R. and Boynton, A. C. 1991. Information architecture: In search of efficient flexibility. 1991. MIS Quarterly. 15(4): 435-42.

Andreu, R. and Ciborra, C. 1996. Organizational learning and core capabilities development: The role of IT. Journal of Strategic Information Systems. 5(2): 111-27.

Balasubramanian, S., Peterson, R. A., and Jarvenpaa, S. L. 2002. Exploring the implications of m-commerce for markets and marketing. Journal of the Academy of Marketing Science. 30(4): $348-61$.

Barras, R. 1986. Towards a theory of innovation in services. Research Policy. 15(4): 161-73.

Bayrak, T. 2013. A decision framework for SME Information Technology (IT) managers: Factors for evaluating whether to outsource internal applications to Application Service Providers. Technology in Society. 35(1): 14-21.

Berry, L. L., Shankar, V., Parish, J. T., Cadwallader, S. and Dotzel, T., 2006. Creating new markets through service innovation. MIT Sloan Management Review. 47(2): 56-63.

Bharadwaj, A. S., 2000. A resource-based perspective on information technology capability and firm performance: An empirical investigation. MIS Quarterly. 24 (1): 169-196.

Bharadwaj, A., El Sawy, O. A., Pavlou, P. A. and Venkatraman, N., 2013. Digital business strategy: Toward a next generation of insights. MIS Quarterly. 37 (2): 471-482.

Bhatt, G. D. and Grover, B. 2005. Types of information technology capabilities and their role in competitive advantage: An empirical study. Journal of Management Information Systems. 22(2): $253-77$.

Bolat, E., 2016. Business practitioners' perspectives on the value of mobile technology. Journal of Customer Behaviour. 15(1): 31-48.

Bolat, E., Kooli, K., and Wright, L. T., 2016. Businesses and mobile social media capability. Journal of Business \& Industrial Marketing. 31(8): 971-981. 
Calantone, R. J., Cavusgil, S. T. and Zhao, Y. 2002. Learning orientation, firm innovation capability, and firm performance. Industrial Marketing Management. 31(6): 515-524.

Chae, H. C., Koh, C. E., and Prybutok, V. R. 2014. Information technology capability and firm performance: contradictory findings and their possible causes. Mis Quarterly. 38(1): 305-326.

Chen, J. S. and Tsou, H. T. 2007. Information technology adoption for service innovation practices and competitive advantage: The case of financial firms. Information Research: An International Electronic Journal. 12(3).

Chen, J. S. and Tsou, H. T. 2012. Performance effects of IT capability, service process innovation, and the mediating role of customer service. Journal of Engeeniring and Technology Management. 29(1): 71-94.

Chen, J.S., Tsou, H.T., and Ching, R. H. H.. 2011. Co-production and its effects on service innovation. Industrial Marketing Management. 40(8): 1331-46.

Chen, Y., Wang, Y., Nevo, S., Benitez-Amado, J., and Kou, G. 2015. IT capabilities and product innovation performance: The roles of corporate entrepreneurship and competitive intensity. Information \& Management. 56(2): 643-657.

Chung, S., Young, L.K. and Choi, J., 2015. Exploring digital creativity in the workspace: the role of enterprise mobile applications on perceived job performance and creativity. Computers in Human Behavior, 42: 93-109.

Churchill Jr, G. A. 1979. A paradigm for developing better measures of marketing constructs. Journal of Marketing Research. 16(1): 64-73.

Clayton, T. 2003. Service innovation: Aiming to win. In Service innovation: Organisational responses to technological opportunities and market imperatives, ed. J. Tidd and F. M. Hull, 113-36. London: Imperial College Press. 
Corbin, J. and Strauss, A. 1990. Grounded theory research: Procedures, canons, and evaluative criteria. Qualitative Sociology. 13(1): 3-21.

Crook, C. W. and Kumar, R. L. 1998. Electronic data intechange: A multi-industry investigation using grounded theory. Information \& Management. 34(2): 75-89.

Day, G. S. 1994. The capabilities of market-driven organizations. Journal of Marketing. 58(4): 37-52.

Den Hertog, P., Van der Aa, W. and De Jong, M. W. 2010. Capabilities for managing service innovation: towards a conceptual framework. Journal of Service Management. 21(4):490514.

Denzin, N. K., and Lincoln, Y. S. 2011. The SAGE handbook of qualitative research. London: Sage.

Dutta, S., Zbaracki, M. J., and Bergen, M. 2003. Pricing process as a capability: A resourcebased perspective. Strategic Management Journal. 24(7): 615-30.

Edvardsson, B., Tronvoll, B. and Gruber, T. 2013. Expanding understanding of service exchange and value co-creation: a social construction approach. Journal of the Academy of Marketing Science. 39(2): 327-339.

Ehrenhard, M., Wijnhoven, F., van den Broek, T. and Stagno, M.Z. 2017. Unlocking how start-ups create business value with mobile applications: Development of an App-enabled Business Innovation Cycle. Technological forecasting and social change. 115: pp.26-36.

Elbeltagi, I., Al Sharji, Y., Hardaker, G., and Elsetouhi, A. 2013. The Role of the OwnerManager in SMEs' Adoption of Information and Communication Technology in the United Arab Emirates. Journal of Global Information Management. 21(2): 23-50.

Feeny, D. F. and Willcocks, L. P. 1998. Core IS capabilities for exploiting information technology. Sloan Management Review. 39(3): 9-21. 
Feijóo, C., Maghiros, I., Abadie, F., and Gómez-Barroso, J. L. 2009. Exploring a heterogeneous and fragmented digital ecosystem: Mobile content. Telematics and Informatics. 26(3): 282-92.

Fleischmann, K., Daniel, R., and Welters, R., 2017. Developing a regional economy through creative industries: innovation capacity in a regional Australian city. Creative Industries Journal.10(2): 119-138.

Foroudi, P., Gupta, S., Nazarian, A. and Duda, M., 2017. Digital technology and marketing management capability: achieving growth in SMEs. Qualitative Market Research: An International Journal, 20(2): 230-246.

Gallouj, F. and Weinstein, O. 1997. Innovation in services. Research Policy. 26(4-5): 537556.

Hamburg, I. and O'Brien, E. 2014. Using strategic learning for achieving growth in SMEs. Journal of information technology and application in education. 3(2): 77-83.

Hameed, K. 2003. The application of mobile computing and technology to health care services. Telematics and Informatics. 20(2): 99-106.

Handke, C. 2007. Surveying innovation in the creative industries. Proceedings of the 5th International EMAEE Conference on Innovation, May 17-19, 2007, Manchester.

Heilig, L. and Voß, S. 2015. A Mobile Cloud Workforce Management System for SMEs. In New Horizons in Design Science: Broadening the Research Agenda (pp. 391-395). Springer International Publishing.

Huang, S. M., Ou, C. S., Chen, C. M. and Lin, B. 2006. An empirical study of relationship between IT investment and firm performance: A resource-based perspective. European Journal of Operational Research. 173(3): 984-999. 
Huang, Y. H., Li, E. Y., and Chen, J. S. 2009. Information synergy as the catalyst between information technology capability and innovativeness: Empirical evidence from the financial service sector. Information Research: An International Electronic Journal. 14(1).

Jayaram, D., Manrai, A. K., and Manrai, L. A. 2015. Effective use of marketing technology in Eastern Europe: Web analytics, social media, customer analytics, digital campaigns and mobile applications. Journal of Economics, Finance and Administrative Science. 20(39): 118-132.

Jones, O., Macpherson, A. and Jayawarna, D. 2014. Resourcing the start-up business: Creating dynamic entrepreneurial learning capabilities. Oxon: Routledge.

Kuppelwieser, V. G., Sarstedt, M., and Tuzovic, S., 2014. The role of context and motivation variables in mobile commerce usage-A further perspective on Chong (2013). Technological Forecasting and Social Change 88: 156-161.

Leahmann, H. and Fernández, F. 2007. Adapting the grounded theory method for information systems research. Proceedings of the 4th QUALIT Conference Qualitative Research in IT and IT in Qualitative Research, November 19-20, 2007, Wellington.

Leonardi, P. M. 2011. When flexible routines meet flexible technologies: Affordance, constraint, and the imbrication of human and material agencies. MIS Quarterly. 35(1): 14767.

Liang, T. P., Huang, C. W., Yeh, Y. H., and Lin, B. 2007. Adoption of mobile technology in business: A fit-viability model. Industrial Management and Data Systems. 107(8): 1154-69.

Lichtenthal, J. D. and Eliaz, S. 2003. Internet integration in business marketing tactics. Industrial Marketing Management. 32(1): 3-13.

Lu, Y. and Ramamurthy, K. 2011. Understanding the link betweennformation technology capability and organisational agility: An empirical examination. MIS Quarterly. 35(4): 93154. 
Lusch, R. F., and Nambisan, S. 2015. Service Innovation: A Service-Dominant Logic Perspective. MIS Quarterly. 39 (1): 155-175.

Martin, P.Y., and Turner, B.A. 1986. Grounded theory and organisational research. Journal of Applied Behavioural science. 22(2): 141-157.

Menzel, H. C., Aaltio, I. and Ulijn, J. M. 2007. On the way to creativity: Engineers as intrapreneurs in organisations. Technovation. 27(12): 732-743.

Nguyen, T. H., Newby, M., and Macaulay, M. J. 2015. Information technology adoption in small business: Confirmation of a proposed framework. Journal of Small Business Management. 53(1): 207-227.

O'Cass, A., Song, M. and Yuan, L. 2013. Anatomy of service innovation: Introduction to the special issue. Journal of Business Research. 66(8): 1060-1062.

Ong, C. S. and Chen, P. Y. 2014. The effects of IT: from performance to value. Industrial Management and Data Systems. 114(1): 70-85.

Ortiz-Villajos, J.M. and Sotoca, S., 2018. Innovation and business survival: A long-term approach. Research Policy, 47(8): 1418-1436.

Partington, D., 2000. Building grounded theories of management action. British Journal of Management. 11(2): 91-102.

Penrose, E. T. 1959. The theory of the growth of the firm. Oxford: Blackwell.

Quigley, S., McRobbie, G., and Watt, K. 2012. Developing business intelligence for Small and Medium Sized Enterprises using mobile technology. In Information Society (i-Society), 2012 International Conference on (pp. 164-167). IEEE.

Rogers, E. M. 2010. Diffusion of innovations ( $4^{\text {th }}$ ed.). London: Simon and Schuster.

Román, S., Rodríguez, R. and Jaramillo, J.F., 2018. Are mobile devices a blessing or a curse? Effects of mobile technology use on salesperson role stress and job satisfaction. Journal of Business \& Industrial Marketing, 33(5): 651-664. 
Schaarschmidt, M., Walsh, G., and Evanschitzky, H. 2018. Customer Interaction and Innovation in Hybrid Offerings: Investigating Moderation and Mediation Effects for Goods and Services Innovation. Journal of Service Research. 21(1): 119-134.

Song, M., Di Benedetto, C. A., and Nason, R. W. 2007. Capabilities and financial performance: the moderating effect of strategic type. Journal of the Academy of the Marketing Science. 35(1): 18-34.

Stadler, C. 2011. Process innovation and integration in process-oriented settings: The case of the oil industry. Journal of Product Innovation Management. 28(1): 44-62.

Tarafdar, M., and Gordon, S. R. 2005. How information technology capabilities influence organisational innovation: Exploratory findings from two case studies. Proccedings for the ECIS Conference, May 26-28, 2005. Regensburg, Germany.

Tarasewich, P., Nickerson, R. C., and Warkentin, M. 2002. Issues in mobile e-commerce. Communications of the Association for Information Systems. 8: 41-64.

Wade, M. and Hulland, J. 2004. Review: the resource-based view and information systems research: review, extension, and suggestions for future research. MIS Quarterly. 28(1): 107142.

Wang, N., Liang, H., Zhong, W., Xue, Y. and Xiao, J. 2012. Resource structuring or capability building? An empirical study of the business value of information technology. Journal of Management Information Systems. 29(2): 325-367.

Wang, E. T. G., Hu, H. F. and Hu, P. J. H. 2013. Examining the role of information technology in cultivating firms' dynamic marketing capabilities. Information and Management. 50(6): 336-343.

Yueh, H.P., Lu, M.H. and Lin, W. 2016. Employees' acceptance of mobile technology in a workplace: an empirical study using SEM and fsQCA. Journal of Business Research, 69(6): $2318-2324$. 
Zhang, M. and Tansuhaj, P. 2007. Organisational culture, information technology capability, and performance: The case of born global firms. The Multinational Business Review. 15(3): 43-77. 
Table 1. Aggregated data on the interviewees' firms

\begin{tabular}{|l|l|l|}
\hline Characteristics & Dimensions & Number of firms \\
\hline \multirow{4}{*}{ Ownership } & Privately held & 20 \\
\cline { 2 - 3 } & Partnership & 9 \\
\cline { 2 - 3 } Number of employees & Public company & 2 \\
\cline { 2 - 3 } & $1-10$ & 17 \\
\cline { 2 - 3 } & $11-50$ & 9 \\
\hline Business context & B2B & 5 \\
\hline Process orientation & Project-based & 31 \\
\hline \multirow{2}{*}{ Founding period } & Before 2000 & 31 \\
\cline { 2 - 3 } & After 2000 & 20 \\
\hline \multirow{2}{*}{$\begin{array}{l}\text { Mobile technology } \\
\text { deployment }\end{array}$} & Negative & 3 \\
\cline { 2 - 3 } & Positive & 28 \\
\hline
\end{tabular}


Table 2. Theoretical concepts emerged from the data

\begin{tabular}{|c|c|c|}
\hline Title of the Concept & References $^{*}$ & Sources $^{* * *}$ \\
\hline Managing operations & 181 & 21 \\
\hline Distinctive characteristics of mobile technology & 153 & 31 \\
\hline Managing projects on the go & 152 & 28 \\
\hline Acquiring mobile technology resources & 140 & 11 \\
\hline Learning & 125 & 28 \\
\hline Mobile technology skills & 123 & 28 \\
\hline Creative spanning of mobile technology resources & 117 & 20 \\
\hline Delivering services and products & 107 & 28 \\
\hline Firm's characteristics & 104 & 31 \\
\hline Client orientation & 97 & 25 \\
\hline Researching market & 97 & 28 \\
\hline Promoting & 96 & 28 \\
\hline Context of deploying mobile technology & 95 & 31 \\
\hline Adhocracy & 92 & 18 \\
\hline Integrating mobile content & 88 & 25 \\
\hline Solving clients' problems & 87 & 28 \\
\hline Respondent's role & 84 & 31 \\
\hline Communicating with customers & 78 & 25 \\
\hline Experimenting & 77 & 15 \\
\hline Using mobile social media & 74 & 17 \\
\hline Communicating & 72 & 27 \\
\hline Firm's portfolio of services & 71 & 31 \\
\hline Learning style & 69 & 28 \\
\hline Accumulating mobile technology resources & 62 & 14 \\
\hline Leading & 59 & 28 \\
\hline Mobile technology hardware & 56 & 28 \\
\hline Values of mobile technology & 55 & 28 \\
\hline Internal social relationships & 54 & 26 \\
\hline Transforming & 54 & 28 \\
\hline Developing content & 52 & 23 \\
\hline
\end{tabular}




\begin{tabular}{|c|c|c|}
\hline Title of the Concept & References $^{*}$ & Sources $^{* * *}$ \\
\hline Tracking competition & 45 & 15 \\
\hline Defining mobile technology & 44 & 31 \\
\hline Mobile technology software & 42 & 28 \\
\hline Defining service innovation & 41 & 22 \\
\hline Stimulating service innovation practices & 41 & 28 \\
\hline Enabling creativity & 41 & 18 \\
\hline Delivering service & 38 & 18 \\
\hline Defining service innovation practices & 35 & 21 \\
\hline Technological orientation & 30 & 15 \\
\hline Business networks and relationships & 29 & 16 \\
\hline Defining mobile technology capabilities & 25 & 16 \\
\hline Maintaining and developing service & 22 & 18 \\
\hline Facilitating service innovation practices & 21 & 13 \\
\hline Extending existing services & 21 & 11 \\
\hline Repackaging existing services & 15 & 8 \\
\hline Industry characteristics & 13 & 6 \\
\hline Developing and delivering new lines of services & 11 & 8 \\
\hline Creating new business (division) & 10 & 8 \\
\hline $\begin{array}{l}\text { Distinctive characteristics of mobile technology - } \\
\text { Negative }\end{array}$ & 8 & 3 \\
\hline Managing projects on the go - Negative & 4 & 3 \\
\hline
\end{tabular}

*Number of text elements referenced as the concept

**Number of sources/interview transcripts wherein the concept was detected 
Table 3. Dimensions of Mobile Technology Deployment in Creative Agencies

\begin{tabular}{|c|c|c|}
\hline Categories & Subcategories & Sources ${ }^{*}$ \\
\hline \multirow{4}{*}{$\begin{array}{l}\text { Mobile } \\
\text { Resources }\end{array}$} & $\begin{array}{l}\text { Mobile technology infrastructure (MTI) } \\
\text { - Hardware } \\
\text { - Software }\end{array}$ & $\begin{array}{l}28 \\
28\end{array}$ \\
\hline & $\begin{array}{l}\text { Organizational culture } \\
\text { - Learning orientation } \\
\text { - Technological orientation } \\
\text { - Client orientation } \\
\text { - Adhocracy }\end{array}$ & $\begin{array}{l}28 \\
15 \\
25 \\
18\end{array}$ \\
\hline & Mobile technology skills & 28 \\
\hline & Business networks and relationships & 16 \\
\hline \multirow{5}{*}{$\begin{array}{l}\text { Mobile Technology } \\
\text { Capabilities }\end{array}$} & Leveraging mobile technology resources & 28 \\
\hline & Transforming & 28 \\
\hline & Learning & 28 \\
\hline & Solving Problems & 28 \\
\hline & Leading & 28 \\
\hline
\end{tabular}

*Number of sources/interview transcripts wherein the concept(s) was/were detected 
Table 4. Mobile technology practices: a three-cluster comparison

\begin{tabular}{|c|c|c|c|}
\hline Sub-categories & $\begin{array}{l}\text { Cluster A } \\
\text { (Firms 6, 8, 9, } \\
\text { 10, 11, 20, 22, } \\
\text { 23, 24, 31) }\end{array}$ & $\begin{array}{l}\text { Cluster B } \\
\text { (Firms 1, 4, 5, 7, 17, 19, } \\
\text { 25, 27, 29, 30) }\end{array}$ & $\begin{array}{l}\text { Cluster C } \\
\text { (Firms 3, 12, 13, 14, } \\
\text { 16, 18, 21, 28) }\end{array}$ \\
\hline \multicolumn{4}{|c|}{ Category: Mobile technology resources } \\
\hline $\begin{array}{l}\text { Mobile technology } \\
\text { infrastructure (MTI) }\end{array}$ & $\begin{array}{l}\text { Cost-free } \\
\text { orientation of } \\
\text { MTI policy }\end{array}$ & $\begin{array}{l}\text { Moderate investment in } \\
\text { MTI: MT-specific } \\
\text { software }\end{array}$ & $\begin{array}{l}\text { Extensive investment in } \\
\text { MTI: software and } \\
\text { hardware }\end{array}$ \\
\hline Organisational culture & $\begin{array}{l}\text { Learning } \\
\text { orientation } \\
\text { Client } \\
\text { orientation - } \\
\text { Responsive }\end{array}$ & $\begin{array}{l}\text { Learning orientation } \\
\text { Client orientation - } \\
\text { Responsive } \\
\text { Technological } \\
\text { orientation- Researching } \\
\text { Adhocracy }\end{array}$ & $\begin{array}{l}\text { Learning orientation } \\
\text { Client orientation - } \\
\text { Proactive } \\
\text { Technological } \\
\text { orientation- Exploring } \\
\text { and experimenting } \\
\text { Adhocracy - } \\
\text { 'Mobilisation' of } \\
\text { business model }\end{array}$ \\
\hline $\begin{array}{l}\text { Mobile technology skills } \\
\text { - In-house skills } \\
\text { - Accessing external } \\
\text { skills }\end{array}$ & $\begin{array}{l}\text { Low } \\
\text { High }\end{array}$ & $\begin{array}{l}\text { High } \\
\text { Low }\end{array}$ & $\begin{array}{l}\text { High } \\
\text { Not present }\end{array}$ \\
\hline $\begin{array}{l}\text { Business network and } \\
\text { relationships } \\
\text { - Internal } \\
\text { - External }\end{array}$ & $\begin{array}{l}\text { Segregation of } \\
\text { duties } \\
\text { High reliance on } \\
\text { external } \\
\text { partnerships }\end{array}$ & $\begin{array}{l}\text { Collaborative } \\
\text { Low reliance on external } \\
\text { partnerships }\end{array}$ & $\begin{array}{l}\text { Interchanging roles \& } \\
\text { responsibilities } \\
\text { Not present }\end{array}$ \\
\hline
\end{tabular}




\begin{tabular}{|c|c|c|c|}
\hline Sub-categories & $\begin{array}{l}\text { Cluster A } \\
\text { (Firms 6, 8, 9, } \\
\text { 10, 11, 20, 22, } \\
23,24,31)\end{array}$ & $\begin{array}{l}\text { Cluster B } \\
\text { (Firms 1, 4, 5, 7, 17, 19, } \\
\text { 25, 27, 29, 30) }\end{array}$ & $\begin{array}{l}\text { Cluster C } \\
(\text { Firms 3, 12, 13, 14, } \\
\text { 16, 18, 21, 28) }\end{array}$ \\
\hline \multicolumn{4}{|c|}{ Category: Mobile technology capabilities } \\
\hline $\begin{array}{l}\text { Leveraging mobile } \\
\text { technology resources }\end{array}$ & $\begin{array}{l}\text { Outsourcing } \\
\text { MTI and mobile } \\
\text { technology } \\
\text { skills }\end{array}$ & $\begin{array}{l}\text { Acquiring MTI software, } \\
\text { acquiring and } \\
\text { outsourcing mobile } \\
\text { technology skills, } \\
\text { creative spanning of } \\
\text { existing expertise with } \\
\text { new MTI }\end{array}$ & $\begin{array}{l}\text { Acquiring and } \\
\text { accumulating MTI and } \\
\text { mobile technology } \\
\text { resources, creative } \\
\text { orchestration of mobile } \\
\text { technology resources to } \\
\text { create unique } \\
\text { combinations }\end{array}$ \\
\hline Transforming & $\begin{array}{l}\text { Operational } \\
\text { process }\end{array}$ & $\begin{array}{l}\text { Operational process } \\
\text { Improving service } \\
\text { offering }\end{array}$ & $\begin{array}{l}\text { 'Mobile' operational } \\
\text { process } \\
\text { New radical service } \\
\text { solutions } \\
\text { New business model }\end{array}$ \\
\hline Learning & $\begin{array}{l}\text { Researching } \\
\text { about mobile } \\
\text { technology } \\
\text { deployment }\end{array}$ & $\begin{array}{l}\text { Researching and } \\
\text { scanning for new ideas } \\
\text { on improving existing } \\
\text { services }\end{array}$ & $\begin{array}{l}\text { Researching and } \\
\text { experimenting with } \\
\text { ideas on developing } \\
\text { new services }\end{array}$ \\
\hline Solving problems & $\begin{array}{l}\text { Objectives set } \\
\text { by clients }\end{array}$ & $\begin{array}{l}\text { Objectives set by clients } \\
\text { with the firm's input }\end{array}$ & $\begin{array}{l}\text { Objectives set by the } \\
\text { firm with clients' input }\end{array}$ \\
\hline Leading & $\begin{array}{l}\text { Compliance } \\
\text { with cost } \\
\text { leadership } \\
\text { strategy - } \\
\text { mobile } \\
\text { technology as } \\
\text { operational tool }\end{array}$ & $\begin{array}{l}\text { Strategic alignment of } \\
\text { mobile technology } \\
\text { specific strategic options } \\
\text { (ethical MT use and } \\
\text { simplification strategy) } \\
\text { with overall business } \\
\text { strategy }\end{array}$ & $\begin{array}{l}\text { Proactive strategic } \\
\text { orientation }\end{array}$ \\
\hline
\end{tabular}

